\title{
Anabases
}

ANABASES Traditions et réceptions de l'Antiquité

28 | 2018

Varia

\section{L'Évangile selon les Juifs : à propos de quelques témoignages anciens}

The Gospel according to the Jews: about some ancient evidence

Daniel Barbu

\section{(2) OpenEdition}

1 Journals

Édition électronique

URL : https://journals.openedition.org/anabases/7779

DOI : 10.4000/anabases. 7779

ISSN : 2256-9421

\section{Éditeur}

E.R.A.S.M.E.

\section{Édition imprimée}

Date de publication : 9 novembre 2018

Pagination : 157-180

ISSN : 1774-4296

\section{Référence électronique}

Daniel Barbu, «L'Évangile selon les Juifs : à propos de quelques témoignages anciens », Anabases [En ligne], 28 | 2018, mis en ligne le 09 novembre 2020, consulté le 21 septembre 2021. URL : http:// journals.openedition.org/anabases/7779; DOI : https://doi.org/10.4000/anabases.7779 
Anabases 28 (2018), p. 157-180.

\section{L'Évangile selon les Juifs : à propos de quelques témoignages anciens}

Daniel BARBU

$\mathrm{D}$ ans sa Lettre sur les Juifs, rédigée vers 1755, Voltaire écrit : “Le Toledos Jeschut (sic) est le plus ancien écrit juif qui nous ait été transmis contre notre religion. C'est une Vie de Jésus-Christ toute contraire à nos saints Évangiles ; elle paraît être du premier siècle, et même écrite avant les Évangiles ; car l'auteur ne parle pas d'eux, et probablement il aurait tâché de les réfuter s'il les avait connus »'. Voltaire se trompait. Les Toledot Yeshu, qu'il lisait dans l'édition de J.-C. Wagenseil, parue en 1681 avec une traduction latine, bien loin d'offrir un accès immédiat à un temps qui précéderait les évangiles, constituent une sorte d'anti-évangile, voire de parodie des évangiles. Cette saga, qui fait de Jésus un bâtard et un magicien mis à mort par les rabbins, nous est connue par une tradition textuelle remarquablement fluide dont les origines demeurent controversées. La recherche se divise en deux fronts, entre ceux qui défendent une datation haute et suggèrent que les Toledot (ou une forme de proto-Toledot) circulaient dès le $\mathrm{II}^{\mathrm{e}}$ ou $\mathrm{III}^{\mathrm{e}} \mathrm{s}$. de notre ère, et ceux qui privilégient une datation plus tardive et avancent que les diverses recensions du texte n'ont pu voir le jour avant la fin de l'Antiquité, voir le début du Moyen Âge ${ }^{2}$. Certains des motifs que développent les Toledot

1 Voltaire, Euvres de 1767, F. Bessire (éd.), Oxford, 2008, vol. 2, p. 470. D. Barbu, "De Jésus à Voltaire. Variations sur les origines du christianisme », in F. Prescendi, Y. Voloknine (dir.), Dans le laboratoire de l'historien des religions. Mélanges offerts à Philippe Borgeaud, Genève, 2011, p. 31-44.

2 Désormais M. Meerson, P. Schäfer (dir.), Toledot Yeshu : The Life Story of Jesus, Tübingen, 2014, avec les réserves de D. StöckL ben Ezra, dans Asdiwal. Revue genevoise d'anthropologie et d'histoire des religions 11 (2016), 226-230. Plusieurs versions des Toledot sont disponibles en traduction française dans J.-P. Osier, L'Évangile du Ghetto, ou comment les Juifs se racontaient Jésus (II ${ }^{e}-X^{e}$ siècles), Paris, 1984. 
sont indubitablement anciens. Reste à savoir quand ils ont été réunis au sein d'une narration cohérente, d'un récit à proprement parler. Il faut dire qu'un tel récit n'est pas attesté avant le $\mathrm{Ix}^{\mathrm{e}}$ siècle, lorsque les évêques de Lyon, Agobard et Amolon, y font référence ${ }^{3}$. Les plus anciens témoins manuscrits $\left(\mathrm{x}^{\mathrm{e}}\right.$ ou XI ${ }^{\mathrm{e}} \mathrm{s}$.), révélés par la Genizah du Caire, confirment la très large circulation, au Moyen Âge, d'au moins deux versions, l'une très proche du texte que connaissaient Agobard et Amolon, l'autre plus proche de celle que citait Voltaire ${ }^{4}$. La plupart des manuscrits sont cependant plus tardifs, ce qui n'a pas empêché la critique de chercher à remonter le temps et restituer l'histoire ancienne des Toledot Yeshu en se fondant notamment sur les rapports intertextuels unissant cette tradition aux sources patristiques et rabbiniques anciennes ${ }^{5}$, ou sur l'analyse linguistique des textes dont nous disposons. Sur ce point, le fait que deux des plus grands spécialistes de dialectologie araméenne s'étant récemment penchés sur cette question soient arrivés à des conclusions tout à fait divergentes devrait cependant inciter à la prudence ${ }^{6}$. Il est peut-être vain de chercher à dater précisément ces

3 Voir B. Blumenkranz, Les auteurs chrétiens latins du Moyen Âge sur les Juifs et le judaïsme, Paris, 2007, p. 163, 167-200, et désormais Agobard, Euvres. Tome 1, M. Rubellin (éd.), Paris, 2016, p. 346-349. À ce sujet, voir P. Schärer, “ Abogard's and Amulo's Toledot Yeshu », in P. SснӓғER et al.(dir.), Toledot Yeshu « The Life Story of Jesus ») Revisited: A Princeton Conference, Tübingen, 2011, p. 27-48. Le texte d'Amolon est malencontreusement attribué à Raban Maur par plusieurs chercheurs, notamment Osier, L'Evangile du Ghetto, p. 157-158.

$4 \quad \mathrm{Au} \mathrm{xIV}^{\mathrm{e}} \mathrm{s}$., le savant juif converti au christianisme Alfonso de Valladolid (anciennement Abner de Burgos), parle encore de deux « livres » distincts. Cf. C.F. SAINZ DE LA MAZA, « El Toledot Yeshu castellano en el Maestre Alfonso de Valladolid », in P. Garciá Alonzo et al. (dir.), Actas II Congreso Internacional de la Asociacion Hispanica de Literature Medieval, Alcalá de Henares, 1987, p. 797-814. Si les fragments araméens livrés par la Genizah du Caire sont bien connus, les fragments judéo-arabes, qui témoignent précisément de la coexistence des deux versions, sont souvent ignorés. Voir M. GoldsteIn, « JudeoArabic Versions of Toledot Yeshu », Ginzei Qedem 6 (2010), p. 9-42.

5 C'est très explicitement le projet de S. Krauss, Das Leben Jesu nach jüdischen Quellen, Berlin, 1902, qui postulait une rédaction au $\mathrm{v}^{\mathrm{e}}-\mathrm{vI}^{\mathrm{e}}$ siècle sur la base de traditions plus anciennes. Il est notamment suivi par D. STöKL Ben Ezra, “Interaction et différenciation. Quelques pensées sur les rôles des fêtes juives, chrétiennes (et "païennes") », in N. Belayche, J.-D. Dubois (dir.), L'oiseau et le poisson. Cohabitations religieuses dans les mondes grec et romain, Paris, 2011, p. 23-37. W. Horbury, A Critical Examination of the Toledoth Jeshu, PhD, Clare College, Cambridge 1970 ; H.I. Newman, "The Death of Jesus in the Toledot Yeshu Literature ", J. Theol. Stud. 50.1 (1999), p. 59-79, deux études par ailleurs remarquables, vont encore plus loin, proposant une rédaction au $\mathrm{II}^{\mathrm{e}}$ ou $\mathrm{III}^{\mathrm{e}} \mathrm{s}$.

6 Cf. W.F. Smelik, “ The Aramaic Dialect(s) of the Toledot Yeshu Fragments », Aramaic 
textes qui résultent d'un «bricolage » littéraire combinant plusieurs micro-récits ayant chacun pu émerger à une autre époque avant de fusionner progressivement et donner naissance aux différentes recensions qui nous sont connues ${ }^{7}$.

Surtout, et comme le révèle la citation de Voltaire, les débats autour de la datation des Toledot sont bien loin d'être neutres ${ }^{8}$. En faisant des Toledot un témoignage historique susceptible d'éclairer les circonstances véritables ayant mené à la naissance du christianisme, celui-ci s’inscrivait, presque malgré lui, dans une tradition vénérable, selon laquelle ces textes - «calomnies atroces » (Pierre Bayle $\left.^{9}\right)$ - recèleraient une part d'Hebraica veritas. Mais l'objectif de Voltaire était évidemment très différent de ses prédécesseurs. Pour lui, il ne s'agissait pas de démontrer qu'“ au milieu de l'Entassement de Fables \& de Mensonges qu'ils ont accumulez, [les Juifs] avouent que Jésus-Christ a fait des Miracles » (Basnage ${ }^{10}$ ), autrement dit, d'exposer que même les Toledot Yeshu attestent de la vérité du Christ, mais bien de contester le récit officiel d'une Église qui aurait corrompu le message de l'homme Jésus (ce “ Socrate de Galilée »), dont elle a fait un Dieu, au moyen d'une source“ défigurée », certes, mais néanmoins " plus croyable, plus naturel[le], plus conforme à ce qui se passe tous les jours dans le monde, qu'aucun des cinquante Évangiles des christicoles " "I. Un peu plus d'un siècle plus tard, les libres penseurs (athées et franchement anti-chrétiens), G.W. Foote et J.M. Wheeler qui publient une traduction anglaise du texte de Wagenseil, lui emboîtent le pas, affirmant : « cet ouvrage porte les marques de l'Antiquité, et d'autre preuves d'une

Stud. 7 (2007), p. 39-73, qui propose une datation au III ou IVe s., et M. Sokoloff, "The Date and Provenance of the Aramaic Toledot Yeshu on the Basis of Aramaic Dialectology », in Schӓғеr et al. (dir.), Toledot Yeshu ... Revisited, p. 13-26, qui opte, lui, pour les vi-viI ${ }^{\mathrm{e}}$ s. Il faut noter que ces études proposent, au mieux, un terminus post quem.

7 R. Di Segni, Il vangelo del Ghetto. Le «storie di Gesù»: leggende e documenti della tradizione medievale ebraica, Roma, 1985, p. 216-217. Voir également J.G. GAGER, “Simon Peter, founder of Christianity or Saviour of Israel ? », in Schäfer et al. (dir.), Toledot Yeshu ... Revisited, p. 221-245. Il faut signaler ici cet autre parodie des évangiles qu'est l'Alphabet de Ben Sira; cf. E. YAssif, “ Toledot Yeshu : Folk-Narrative as Polemics and Self Criticism », in SchäFer et al.(dir.), Toledot Yeshu ... Revisited, p. 101-135.

8 Voir sur ce point W. Horbury, "Titles and Origins of Toledot Yeshu ", in D. Barbu, Y. Deutsch (dir.), The Jewish Life of Jesus (Toledot Yeshu) in Context, Tübingen, à paraître.

9 Lettres de Mr. Bayle, P. Maizeaux (éd.), Amsterdam, 1729, p. 1031 (6 août 1705 à ****).

10 J. de Basnage, Histoire des Juifs, depuis Jésus-Christ jusqu'à présent. Pour servir de continuation à l'Histoire de Joseph, La Haye, 1716, tome V, p. 287.

11 Voltaire, L'Examen important de Milord Bolingbroke, dans Euvres de 1766-1767, J. Marchand et al. (éd), Oxford, 1987, p. 214. 
bien meilleure connaissance des manières, coutumes et opinions des Juifs de Palestine que celle que trahissent nos évangiles grecs » ${ }^{12}$.

Les intellectuels juifs ont longtemps plutôt eu tendance à contester l'antiquité des Toledot. Ils pouvaient en cela s'appuyer sur l'opinion de Wagenseil luimême, pour lequel : est omnino recens hic abortus, \& per paucorum seculorum, “ cet avorton est tout à fait récent, et vieux d'à peine quelques siècles » ${ }^{13}$. Dans sa célèbre controverse avec le pasteur suisse Johann Kaspar Lavater, le philosophe juif Moïse Mendelssohn faisait sans doute écho à ces propos en affirmant que les Toledot n'étaient rien d'autre qu'un « avorton du temps des légendes, et dignes de cet âge » (eine Mißgeburt aus den Zeiten der Legenden, und ihrer würdig) ${ }^{14}$. C'est là plus ou moins l'opinion unanime des grandes figures, au xIx ${ }^{\mathrm{e}}$ s., de la Wissenschaft des Judentums. Samuel Krauss, qui le premier, en 1902, consacra une monographie à ce corpus, rompt avec cette tradition. Son étude, qui se veut d'abord philologique, propose de dater les Toledot Yeshu aux derniers siècles de l'Antiquité ; et surtout d'en exposer les “ sources chrétiennes »15. Cette opinion n'a certes pas suscité l'unanimité. La question dépend largement du lien qu'on se figure exister (ou non) entre les Toledot et les témoignages anciens relatifs à ce que les Juifs rapportent (ou sont dits rapporter) de Jésus.

Avant toute chose il faut cependant signaler que si les Juifs et le judaïsme sont un objet constant de réflexion pour le christianisme ancien, l'inverse n'est pas forcément vrai. Les Juifs ne parlent guère du christianisme en tant que tel avant le $\mathrm{IV}^{\mathrm{e}}$ ou $\mathrm{v}^{\mathrm{e}}$ siècle, et à vrai dire, encore moins de Jésus ${ }^{16}$. Du moins ces Juifs dont les écrits sont parvenus jusqu'à nous. À la différence des auteurs chrétiens des premiers siècles, pour lesquels les Juifs et le judaïsme constituent une forme d'obsession, les premiers rabbins semblent presque indifférents aux chrétiens. Il faut en fait attendre le vıII ${ }^{\mathrm{e}}$ ou $\mathrm{Ix}^{\mathrm{e}}$ siècle, pourvoir apparaître des traités de polémique juive anti-chrétienne, qui fassent en quelque sorte pendant au genre de l'Adversus iudaeos, entre-temps devenu incontournable pour tout théologien chrétien qui

12 J.M. Wheeler, G.W. Foote, The Jewish Life of Christ : Being the Sepher Toldoth Jeshu, or, Book of the Generation of Jesus, London, 1885.

13 J.C. WAgEnseil (éd.), Tela ignea Satanae : hoc est Arcani et horribiles Judaeorum adversus Christum Deum et christianam religionem libri anekdotoi, Altdorf, 1681, vol. 2.

14 M. Mendelssohn, Schriften zum Judentum, vol. 1, Berlin, 1930, p. 362 (lettre à K. Lavater du 15 janvier 1771).

15 Krauss, Leben Jesu, p. 2. Sur l'ouvrage de Krauss, cf. Y. Moss, "I am not Writing an Apology:" Samuel Krauss's Das Leben Jesu in Context ", in Barbu, Deutsch (dir.), Toledot Yeshu in Context, à paraître.

16 Voir l'étude exhaustive de T. Murcia, Jésus dans le Talmud et dans la littérature rabbinique ancienne, Turnhout, 2014. Voir également P. SchäfEr, Jesus in the Talmud, Princeton, N.J., 2007. 
se respecte ${ }^{17}$. Rien de tel, donc, dans l'Antiquité : l'effort des premiers rabbins porte ailleurs, dans l'élaboration d'un système théologique cohérent fondé sur l'interprétation de la Loi orale dont ils sont les gardiens ${ }^{18}$. Néanmoins, il n'est pas impossible de détecter, très tôt, dans la littérature rabbinique, et en particulier dans l'exégèse de la bible (le midrash), une volonté de répondre voire de contester le point de vue chrétien. Pour ce faire, il faut, nous dit Israël Yuval, accorder son oreille à des notes plus ténues, aux bruissements subtils et autres allusions s'efforçant de répondre aux arguments des « hérétiques » ${ }^{19}$. Ce que l'on entendra ainsi, ce sont moins des attaques explicites, que l'insistant rappel de l'élection d'Israël, de l'alliance indéfectible de Dieu avec son peuple ${ }^{20}$. Mais si la littérature rabbinique ancienne semble offrir plusieurs points de contre-exégèse à l'exégèse chrétienne des Écritures, elle ne s'attelle guère à offrir un contre-discours des origines du christianisme. Nous avons bien, ci et là, de possibles allusions à Jésus, mais celles-ci se concentrent dans le Talmud de Babylone, compilé entre le $\mathrm{v}^{\mathrm{e}}$ et le vi ${ }^{e}$ siècle ${ }^{21}$. Dans les textes plus anciens, ces allusions (s'il s'agit bien d'allusions

17 On compte plusieurs dizaines de traités portant ce titre ou un titre analogue entre le $\mathrm{II}^{\mathrm{e}}$ et le $\mathrm{xi}^{\mathrm{e}}$ s. Cf. H. Schreckennerg, Die christlichen Adversus-Judaeos-Texte und ihr literarisches Umfeld (1-11.Jh.), Frankfurt am Main, 1982. De manière générale, voir S. Krauss, W. Horbury, The Jewish-Christian Controversy: From the Earliest Times to 1789, Tübingen, 2008. Sur l'émergence de traités de controverse juifs dans les premiers siècles de l'islam, cf. D.J. Lasker, “ The Jewish Critique of Christianity under Islam in the Middle Ages ", Proc. Am. Acad. Jew. Res. 57 (1990), p. 121-153 et D.J. Lasker, S. Stroumsa, The Polemic of Nestor the Priest: Qișșat mujādalat al-usquf and Sefer Nestor ha-Komer, Jérusalem, 1996, p. 14-15.

18 Le fait que ce processus doive néanmoins être lu à la lumière de l'effort concomitant des premiers intellectuels chrétiens d'établir leur propre interprétation de la Loi et ainsi poser les bases du christianisme a été suggéré, notamment, par G.G. Stroumsa, Le rire du Christ : essais sur le christianisme antique, Paris, 2006 (chap. 5) ; D. Boyarin, La partition du judaïsme et du christianisme, Paris, 2011.

19 I.J. Yuval, “Deux peuples en ton sein ». Juifs et chrétiens au Moyen Âge, Paris, 2012.

20 Également A. Marmorstein, "Judaism and Christianity in the Middle of the Third Century ", Hebr. Union Coll. Annu. 10 (1935), p. 223-263 ; B.L. Visotzky, Fathers of the World: Essays in Rabbinic and Patristic Literatures, Tübingen, 1995 ; D. Boyarin, La partition du judaïsme et du christianisme, Paris, 2011 ; H.M. Zellentin, Rabbinic Parodies of Jewish and Christian literature, Tübingen, 2011.

21 Schäfer, Jesus in the Talmud,passim ; cf. également R. Kalmin, "Christians and Heretics in Rabbinic Literature of Late Antiquity », Harv. Theol. Rev. 87.2 (1994), p. 155-169 ; ID., “Jesus in Sasanian Babylonia », Jew. Q. Rev. 99.1 (2009), p. 107-112. À cet égard, les sources babyloniennes reflètent sans doute l'intensification de la controverse judéochrétienne dans le contexte sassanide à partir du $\mathrm{IV}^{\mathrm{e}} \mathrm{s}$. ; voir notamment J. Neusner, “ Babylonian Jewry and Shapur II's Persecution of Christianity from 339 to 379 A.D. », 
à Jésus) reflètent aussi une préoccupation davantage normative que proprement polémique : on y apprend surtout que lorsqu'un rabbin flirte avec l'hérésie (minut), il doit en payer le prix ${ }^{22}$.

Très peu, donc, de références directes à Jésus, dans la littérature juive des premiers siècles - si l'on exclut bien sûr les évangiles néotestamentaires et un passage controversé des Antiquités juives de Flavius Josèphe (XVIII, 63-64) ${ }^{23}$. Mais si les textes juifs ne disent rien, les textes chrétiens, eux, s'engagent dans un intense exercice de ventriloquisme ${ }^{24}$.

\section{Justin et les calomnies des Juifs}

Ainsi le philosophe chrétien Justin, qui dans son fameux « dialogue » avec le Juif Tryphon, composé autour de 150, accuse les Juifs de calomnier les chrétiens :

Après l'avoir crucifié, lui seul homme sans tache et juste, dont les meurtrissures

Hebr. Union Coll. Annu. 43 (1972), p. 77-102 ; J.M. Fiev, « Juifs et chrétiens dans l’Orient Syriaque », Hisp. Sacra 40.82 (1988), p. 933-953 ; S. Minov, Syriac Christian Identity in Late Sasanian Mesopotamia: The Cave of Treasures in Context, Thèse de doctorat, Université hébraïque de Jérusalem, 2013, p. 167-181 ; A.H. Becker, "L’antijudaïsme syriaque : entre polémique et critique interne », in F. RuANi (dir.), Les controverses religieuses en syriaque, Paris, 2016, p. 181-207.

22 Voir par exemple Tosefta, Hullin 2, 22-23 : « Récit de R. Eléazar b. Dama qu’un serpent mordit. Vint Jacob de Kephar Sama pour le guérir au nom de Yeshua' b. Panthera. Mais rabbi Ismaël ne le permit pas. Il lui dit: “Tu n'es pas autorisé b. Dama." Celuici répondit : “J'apporterai une preuve scripturaire qu'il peut le faire." Mais il mourut avant d'apporter cette preuve. R. Ismaël s'exclama : “Heureux es-tu, b. Dama, d'être sorti de ce monde en paix, sans avoir détruit la haie des Sages! » (trad. Murcia).

23 S. BARdet, Le Testimonium flavianum: examen historique, considérations historiographiques, Paris, 2002.

24 H.L. Strack, Jesus, die Häretiker und die Christen nach den ältesten jüdischen Angaben : Texte, Übersetzungen und Erläuterungen, Leipzig, 1910, p. 8*-13* (Pères grecs) et $14^{*}-17^{*}$ (Pères latins); et les références supplémentaires signalées par W. Horbury, "Tertullian on the Jews in the Light of De Spec. xxx. 13 ", J. Theol. Stud. 23 (1972), p. 455-459. Parmi celles-ci, cf. notamment Origène, Commentaire sur l'Évangile de Jean 20, 16 (14); Évangile de Thomas 105 (Jésus fais allusion au fait qu'il est appelé “ fils d'une prostituée » par les Juifs); Martyre de Conon 4, 6 (“Pourquoi errez-vous en disant d'un homme qu'il est un dieu, mort de mort violente qui plus est? J'ai appris des Juifs ce qu'il en est vraiment, quelle fut sa famille, tout ce qu'il a dit à leur peuple, et comment il est mort crucifié »). La pique adressée par Jérôme, Commentaire sur l'épître à Tite, 3, 9 à “ certains Juifs, qui, à Rome, feignent de croire en Christ, et questionnent la généalogie de notre Seigneur Jésus Christ telle qu'elle figure dans Matthieu et Luc » s'adresse vraisemblablement à Ambrosiaster ; S. Lunn-Rockliffe, Ambrosiaster's Political Theology, Oxford, 2009, p. 24. 
procurent la guérison à ceux qui par lui vont vers le Père, quand vous avez appris qu'il était ressuscité des morts et monté au ciel, conformément à ce qu'annonçaient les prophéties, non seulement vous ne vous êtes pas repentis (metonêsate) de vos mauvaises actions, mais vous avez alors, de Jérusalem, désigné des hommes choisis que vous avez envoyés par toute la terre pour dire qu'une hérésie impie (hairesin atheon), celle des "chrétiens », était apparue, et débiter les accusations que répandent sur notre compte tous ceux qui ne nous connaissent pas (Dialogue 17, 1 ; trad. Bовісном). ${ }^{25}$

On ne sait trop quel crédit accorder à ces propos; ou plutôt, on ne sait que trop bien combien l'accusation que Justin formule ici doit être considérée avec prudence. À plusieurs reprises, Justin répète en effet que les Juifs, coupables d'avoir persécuté et tué Jésus ${ }^{26}$, le Messie annoncé par leurs propres prophètes, n'ont de cesse de s'opposer aux chrétiens ${ }^{27}$. Les Juifs, écrit Justin, travaillent obstinément à profaner le nom du Christ. Il ajoute :

Or, non seulement vous ne vous êtes pas repentis, après avoir appris qu'il était ressuscité des morts, mais, comme je l'ai déjà dit, vous avez choisi, en les élisant, des hommes qui furent envoyés par toute la terre habitée. Ils proclamaient qu'une hérésie qui détourne de Dieu et de la Loi avait été suscitée par la séduction d'un certain Jésus, Galiléen ; quand nous l'eûmes crucifié, disaient-ils, ses disciples le dérobèrent, pendant la nuit, du tombeau dans lequel il avait été placé après avoir été décloué de la Croix : et ils égarent les hommes en affirmant qu'il est réveillé des morts et monté au ciel (Dialogue 108, 2 ; trad. Вовісном).

Les Juifs nient la résurrection donc, dont ils font une supercherie inventée

25 Le passage est repris chez Eusèbe de Césarée, Histoire ecclésiastique IV, 18, 6-7 et cf. Id., Commentaire sur Isaïe 18, 1-2 (119). Sur Justin et les Juifs, cf. J. Lieu, « Accusations of Jewish Persecution in Early Christian Sources, With Particular Reference to Justin Martyr and the Martyrdom of Polycarp ", in G.N. Stanton, G.G. Stroumsa (dir.), Tolerance and Intolerance in Early Judaism and Christianity, Cambridge, 1998, p. 279-295 ; D. Boyarin, “Justin Martyr Invents Judaism », Church Hist. 70.3 (2001), p. 427-461; Р. Вовісноn, “Persécutions, calomnies, "Birkat ha-Minim” et émissaires juifs de propagande anti-chrétienne dans les écrits de Justin Martyr », Revue des Études Juives 162 (2003), p. 403-419. Les textes patristiques relatifs aux juifs sont réunis dans S. Krauss, "The Jews in the Works of the Church Fathers ", Jew. Q. Rev. 5.6 (1893), p. 122-157, 82-99, 225-261.

26 Dialogue 72, 3 : « Et quand il est démontré, d'après ces paroles aussi, que les juifs ont tenu conseil sur la personne du Christ, décidant de le crucifier et de le mettre à mort ». Voir également Dialogue 136, 2 ; 1 Apologie 49, 5. L’accusation de déicide se rencontre déjà chez Méliton de Sardes.

27 Dialogue 95, 4 : « Vous le maudissez, lui (le Christ) et ceux qui croient en lui, (et) chaque fois que vous en avez le pouvoir, vous les mettez à mort ». Voir encore Dialogue 16, 4 ; 26, 1 ; 47, 4 ; 93, 4-5 ; 96, 2 ; 122, 2 ; 133, 6 ; 137, 2 ; 1 Apologie 31, 5-6 ; 36, 1-3. 
par les disciples de Jésus ; ailleurs on apprend encore qu'ils reprochent à Jésus de n'avoir été qu'un magicien qui aurait égaré le peuple (Dialogue 69, 7 : magos kai laoplanos $)^{\mathbf{2 8}}$. Nombre d'historiens du christianisme ont pris les accusations de Justin au pied de la lettre. Mais comme l'a noté Judith Lieu, la question qu'il convient de poser, ici, est moins historique - les Juifs persécutaient-t-ils les chrétiens? - que théologique : pourquoi est-il si important pour Justin de souligner l'opposition des Juifs? ${ }^{29}$

Il faut évidemment rappeler que le Dialogue avec Tryphon de Justin, savante composition littéraire, n'est pas nécessairement le reflet de confrontations réelles entre chrétiens et Juifs ; il en va d'ailleurs de même pour la plupart des traités de polémique antijuive mentionnés plus haut. Ce que ces textes reflètent, ce sont d'abord des conflits internes au christianisme ancien, mais auxquels les théologiens chrétiens, de façon caractéristique, donnent la forme littéraire d'un conflit avec les Juifs - ceux-ci incarnant, déjà chez Paul, une attitude presque symptomatique, une manière erronée de lire et comprendre l'Écriture ${ }^{30}$. Et c'est bien en réponse à la question du statut des Écritures, soulevée comme on le sait $\mathrm{au}$ début $\mathrm{du} \mathrm{II}^{\mathrm{e}} \mathrm{s}$. par Marcion - qui rejetait purement et simplement ce que l'on appelle l'Ancien Testament et son démiurge colérique et vindicatif -, que Justin compose son Dialogue, où il cherche à montrer que les prophéties bibliques annoncent bien la venue du Christ. Pour Justin, c'est Marcion qui se trompe en succombant à une lecture littérale de la Bible et en étant incapable d'en découvrir le véritable sens spirituel ; en d'autres termes, si Marcion ne voit dans le dieu des Écritures juives qu'un dieu sensible et charnel, c'est parce que lui-même les lit “ en Juif », c'est-à-dire en aveugle. Si la Loi a la forme qu'on lui connaît, avec ses innombrables lois et prescriptions que les Juifs prennent au pied de la lettre, c'est en raison du cœur dur et ingrat de ce peuple à la nuque raide auquel Dieu l'a révélée $^{31}$. Mais pour qui sait les lire, la Loi et les Prophètes figurent et annoncent la venue du Christ et la conversion des Nations.

28 Également Dialogue 108, 2; 1 Apologie 30. Justin reprend évidemment ici la donnée néotestamentaire : voir Mt. 9, 34 ; 12, 24 ; Mc. 3, 22 ; Luc 11, 15 et Mt. 27, 63 ; Luc 23, 2 ; Jn. 12, 47. Sur l'accusation de magie, voir M. Sмгтн, Jesus the Magician, London, 1978 ; G.N. Stanton, Jesus and Gospel, Cambridge, 2004, p. 127-147.

29 J. Lieu, “ Accusations of Jewish Persecution », p. 279-280.

30 Sur l'histoire de ce discours, désormais D. Nirenberg, Anti-Judaism: the Western tradition, New York, 2013. Egalement P.C. Bori, Il vitello d'oro : le radici della controversia antigiudaica, Torino, 1983.

31 Dialogue 18,2 ; 27, 2-4 ; 39, 1 ; 43, 1 ; 44, 1 ; 44, 2 ; 45, 3 ; 46, 5-7 ; 47, 2 ; 53, 2 ; 67, 4.8.10 ; 114, 4. 
En ce sens, la haine implacable des Juifs contre Jésus et contre les chrétiens est d'abord, chez Justin, une justification du fait que ce qu'annoncent les prophètes bibliques s'est réalisé, et continue de se réaliser ${ }^{32}$. L'insistance de Justin sur les persécutions que les Juifs font subir aux chrétiens, souligne encore une fois la continuité entre l'Ancien et le Nouveau Testament ; car rien ne prouve davantage le caractère véritablement divin et prophétique du Christ, que le fait qu'il ait été rejeté, persécuté et même tué par son propre peuple, conformément au modèle typologique qu'offrent les prophéties bibliques. L'argument, évidemment, était déjà formulé dans les Évangiles : “ C'est pourquoi la sagesse de Dieu a dit : Je leur enverrai des prophètes et des apôtres ; ils tueront les uns et persécuteront les autres » (Luc 11, 49 ; cf. Luc 6, 22-23 ; Mt. 5, 11 ; 23, 7) ; et avant cela, dans l'un des premiers textes de Paul : “ Ce sont ces Juifs qui ont fait mourir le Seigneur Jésus et les prophètes, qui nous ont persécutés, qui ne plaisent point à Dieu, et qui sont ennemis de tous les hommes » (1 Thess. 2, 15). Justin, on le voit, s'inscrit dans une tradition bien établie lorsqu il accuse les Juifs de poursuivre les chrétiens de leur haine : “ Heureux serez-vous, lorsque les hommes vous hä̈ront, lorsqu'on vous chassera, vous outragera, et qu'on rejettera votre nom comme infâme, à cause du Fils de l'homme! Réjouissez-vous ce jour-là et tressaillez d'allégresse, parce que votre récompense sera grande dans le ciel ; car c'est ainsi que leurs pères traitaient les prophètes » (Luc 6, 22-23 ; cf. Mt. 5, 11). L'hostilité des Juifs est la preuve de la vérité et de l'accomplissement des prophéties. Justin établit pour les Juifs une continuité de caractère et de responsabilité qui trouve ses racines dans les Écritures et se prolonge jusqu'au présent ${ }^{33}$.

Le motif selon lequel les Juifs répandent des calomnies contre les chrétiens participe de ce schéma, et vient confirmer la prophétie d'Isaïe : “Par vous mon

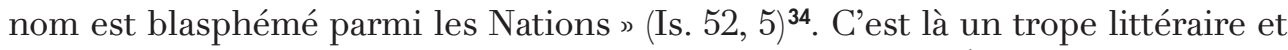
théologique que reprendront bientôt en cœur les Pères de l'Église ${ }^{35}$.

32 P. Fredriksen, "What "Parting of the Ways"? Jews, Gentiles, and the Ancient Mediterranean City ", in A.H. Becker, A. Yoshiko Reed (dir.), The Ways that Never Parted: Jews and Christians in Late Antiquity and the Early Middle Ages, Tübingen, 2007, p. 35-63, en particulier p. 57-58

33 J. Lieu, “Accusations of Jewish Persecution », 282-284. Voir aussi Martyre de Polycarpe 12-13, 17-18 et Martyre de Pionnius 13 avec E.L. Gibson, "Jewish Antagonism or Christian Polemic : The Case of the Martyrdom of Pionius ", J. Early Christ. Stud. 9.3 (2001), p. 339-358.

34 Aussi Isaïe 57, sur la mise à mort du Juste, thème repris par Justin en Dialogue 16.

35 Epître à Diognète V, 17 ; Tertullien, Scorpiace 10 ; Aux Nations I, 14 ; Contre les Juifs 13 ; Irénée de Lyon, Contre les hérésies IV, 28, 3 ; Eusèbe de Césarée, Histoire ecclésiastique $\mathrm{V}, 16,12$. 
L'on a évidemment pu penser que les propos sur Jésus que Justin attribue aux Juifs reflètent effectivement un discours anti-chrétien, tel qu'il a pu circuler $\mathrm{au} \mathrm{II}^{\mathrm{e}}$ s., et selon lequel 1) Jésus était un magicien, voire un faux prophète qui cherchait à égarer le peuple (cf. Dt. 13,5); et 2) ses disciples ont dérobé son corps afin de faire croire qu'il était ressuscité. Mais force est de constater qu'il n'y rien là qui aille au-delà des accusations que les évangiles, déjà, attribuent aux adversaires de Jésus - ou, si l'on préfère, qui aille au-delà des accusations que les évangiles, déjà, s'attèlent à réfuter (cf. Jn. 7, 12: les Juifs accusent Jésus d'égarer la multitude [également Luc 23, 4; 14] ; ou Mt. 26, 63-66 : le tombeau de Jésus est scellé pour empêcher que ses disciples ne dérobent son corps et le déclarent ressuscité) ${ }^{36}$. Les mêmes thèmes sont d'ailleurs développés de manière plus prononcée encore dans certains évangiles apocryphes ${ }^{37}$.

Il est vrai que certaines des accusations relayées par Justin se trouvent effectivement formulées dans les sources juives plus tardives, et notamment les Toledot Yeshu ${ }^{38}$; mais il parait plus convaincant de penser que, ce faisant, ces sources ne témoignent pas nécessairement de la persistance d'une tradition polémique ancienne dontJustin (ou les évangélistes) auraient déjà eu connaissance, mais plus simplement, reflètent une même lecture attentive quoiqu'à contrecourant, des textes chrétiens ; une lecture polémique, donc, qui reprend et assume pleinement les arguments que les évangiles déjà attribuent aux adversaires de Jésus ${ }^{39}$. Évidemment, rien ne nous permet non plus d'exclure la possibilité que certains Juifs aient pu, dès le II ${ }^{\mathrm{e}}$ siècle, lire et critiquer les évangiles.

\section{Le Juif de Celse}

Une génération après Justin, le païen Celse est à cet égard plus précis. Celse, on le sait, est l'un des premiers intellectuels du monde romain à s'être sérieusement penché sur le christianisme : mais son Discours véritable (Logos alêthês) contre les chrétiens, composé vers 178 , ne nous est connu que par la réfutation qu'en fit Origène, près de quatre-vingt ans plus tard. Remarquablement, chez Celse également, la confrontation avec le christianisme passe par un discours juif. C'est un Juif, en effet, qui pour une bonne part lui fournit ses arguments. Du moins estce là ce qu'affirme Origène, qui est d'ailleurs prompt à accuser Celse d'avoir, avec son Juif, abusé de " prosopopées », et fabriqué un personnage dépourvu de toute

36 L'accusation de magie rapportée en 69, 7 et 1 Apol. 30 est plus problématique, car elle n'est jamais formulée explicitement dans le Nouveau Testament. Voir néanmoins Mc. 3, 22 ; Mt. 9, 34; 12, 24 ; Luc 11, 15 ; Jn. 8, 48 ; 52 ; 7, 20 ; 10, 20.

37 Actes de Thomas $96 ; 102 ; 106-107$; Actes de Pilate, passim.

38 Voir par exemple, dans le Talmud de Babylone, Sanh. 43a et 107b (Jésus pendu la veille de Pâques pour avoir pratiqué la magie et dévoyé le peuple).

39 C. Stanton, Jesus and Gospel, p. 132. 
vraisemblance, « qui adresse à Jésus des propos puérils indignes d'un philosophe grisonnant $~^{40}$. Celse, nous dit Origène, “ présente ... un Juif en dialogue avec Jésus lui-même, prétendant le convaincre de plusieurs choses, et la première, d'avoir inventé (plasmenou) sa naissance d'une vierge. Puis il lui reproche d'être issu d'un bourg de Judée, et né d'une femme du pays, pauvre fileuse. Il affirme : Convaincue d'adultère, elle fut chassée par son mari, charpentier de son état. Il dit ensuite que rejetée par son mari, honteusement vagabonde, elle donna naissance à Jésus en secret ; que celui-ci fut obligé, par pauvreté, d'aller louer ses services en Égypte; il y acquit l'expérience de certains pouvoirs magiques dont se targuent les Égyptiens; il s'en revint, tout enorgueilli de ces pouvoirs, et grâce à eux, il se proclama Dieu ” (I, 28 ; trad. BORRET) ${ }^{41}$.

Le Juif de Celse a suscité une littérature infinie ${ }^{42}$. Nombre de savants ont considéré qu'il s'agit en effet d'un personnage fictif, inventé par Celse pour les besoins de sa polémique contre le christianisme. Pourquoi ? Peut-être parce que le fait de laisser parler un “ informateur indigène »-pour Celse, après tout, les chrétiens sont d'abord des Juifs dégénérés - accrédite en quelque sorte le discours " véritable » que l'auteur prétend formuler. Mais on est en droit d'en douter. Il est vrai que, dans une certaine mesure, Celse inclut les Juifs, avec les Perses, les Babyloniens et les Égyptiens, etc., au rang des sagesses barbares, susceptibles donc de fournir un témoignage d'autorité ; mais en réalité, sa perspective sur les Juifs et le judaïsme est plutôt défavorable - ce qui d'ailleurs fait sens dans un contexte où la dernière guerre des Juifs contre les Romains (la révolte dite de Bar-Kokhba, en 133-135) est encore bien présente dans les mémoires ${ }^{43}$. Il reproche notamment à Moïse (qu'il qualifie d'ailleurs de “ sorcier ») d'avoir emprunté l'essentiel de sa doctrine aux anciens sages, et institué des rites à l'imitation des rites égyptiens (car les Juifs, rappelle-t-il, sont d'abord des Égyptiens qui ont abandonné les lois de

40 Origène, Contre Celse I, 28 ; cf. également II, 1.28.54.

41 Pour Origène, qui dénonce à maintes reprises le ridicule des propos tenus par ce Juif, ceux-ci n’en sont pas moins " en harmonie avec le fait que Jésus a été un être divin et digne d'être proclamé fils de Dieu » (ibid.).

42 Voir notamment E. Bammel, "Der Jude des Celsus », in Id., Judaica. Kleine Schriften, Tübingen, 1986, p. 265-283 ; L. Troiani, “Il Giudeo di Celso », in L. Perrone (dir.), Discorsi di verità. Paganesimo, giudaismo e cristianesimo a confrontanel Contra Celso di Origene. Atti del Convegno del Gruppo Italiano di Ricerca su Origene e la Tradizione Alessandrina, Roma, 1998, p. 115-128 ; L. Blumell, “ A Jew in Celsus' True Doctrine? An Examination of Jewish Anti-Christian Polemic in the Second Century C.E. ", Stud. Relig. 36.2 (2007), p. 297-315.

43 Voir M. Stern, Greek and Latin Authors on Jews and Judaism, Jérusalem, 1974, vol. 2, p. 224-305. 
leur première patrie) ${ }^{44}$. Sa cosmogonie, nous dit-il, est puérile; et ce que luimême et les prophètes qui l'ont suivi ont écrit de l'histoire des Juifs témoigne d'un biais qui frise l'imposture. Les Juifs ignorants, répète Celse, se sont laissés séduire par la « magie » ou l'“ imposture » (goêteia) de Moïse. ${ }^{45}$ On ne voit pas très bien pourquoi, dès lors, le même Celse recourrait aux propos d'un Juif en vue d'accréditer ses arguments contre les chrétiens, qui, dit-il, se sont détournés des Juifs après s'être eux-mêmes laissés séduire par un autre “ charlatan " (goês) se prétendant fils de Dieu ${ }^{46}$.

Dans un article récent, Maren Niehoff, a fermement défendu l'idée selon laquelle Celse disposait bien d'une source écrite, composée, selon elle, vers 150, à Alexandrie, par un auteur exercé à la tradition philologique alexandrine, ici déployée pour réfuter les évangiles chrétiens et pointer du doigt leurs contradictions ${ }^{47}$. Le Juif de Celse donnerait ainsi effectivement à voir une première réaction juive à l'émergence du mouvement chrétien, dans un milieu judéo-alexandrin certes affaibli par les révoltes diasporiques de 115-117, mais non encore éteint, et dont la voix nous parvient à travers le double filtre de Celse et d'Origène. Les accusations que ceux-ci mettent dans sa bouche semblent par ailleurs former un ensemble cohérent (et ne sont pas sans rappeler ce que disait Justin) : le Juif de Celse accuse Jésus d'être un sorcier ou un magicien ayant égaré le peuple en se proclamant fils de Dieu ${ }^{48}$. À quoi s'ajoute toutefois cette donnée supplémentaire : Jésus n'est pas issu d'une vierge mais est bien un enfant illégitime. Il faut évidemment nous arrêter quelque peu sur ce point.

Les doutes quant à la naissance de Jésus sont, on le sait, au moins aussi anciens que les textes du Nouveau Testament ${ }^{49}$. “ Ton père, où est-il ? » demandent les

44 Origène, Contre Celse I, 21.23 ; III, 5-8 ; IV, 31 ; V, 25.41. Celse Reprend ici une tradition anti-juive bien attestée depuis Manéthon jusqu'à Tacite, qui font des Juifs des Égyptiens ayant quitté l'Égypte sous la tutelle de Moïse. Cf. notamment R.S. BLoch, Antike Vorstellungen vom Judentum : der Judenexkurs des Tacitus im Rahmen der griechischrömischen Ethnographie, Stuttgart, 2002 ; P. SсHÄFER, Judéophobie : attitudes à l'égard des Juifs dans le monde antique, Paris, 2003 ; Ph. Borgeaud, Aux origines de l'histoire des religions, 2004; D. BARBu, "The Jewish Sacking of Alien Temples : "Limits of Toleration" in a Comparative Perspective », Hist. Relig. 50.1 (2010), p. 21-42.

45 Origène, Contre Celse V, 41-42. Voir également I, 23.26.45 ; III, 5 ; IV, 33.

46 Origène, Contre Celse VIII, 41. Voir également II, 1.53 ; VI, 42 ; VII, 9.36.

47 M.R. Nienoff, “A Jewish Critique of Christianity from Second-Century Alexandria : Revisiting the Jew Mentioned in Contra Celsum ", J. Early Christ. Stud. 21.2 (2013), p. $151-175$.

48 Voir Origène, Contre Celse 1, 28.71 ; II, 1.4.44; VIII, 41.

49 P.-B. Sмiт, « Something about Mary? Remarks about the Five Women in the Matthean Genealogy », New Testam. Stud. 56.2 (2010), p. 191-207 ; J.G. Gager, M. Ahuvia, "Some 
Pharisiens à Jésus en Jean 8,19. On notera que dans l'Évangile de Marc (6, 3), le plus ancien des évangiles, Jésus est appelé « le charpentier, le fils de Marie, le frère de Jacques, de Joses, de Jude et de Simon ». Jésus a une mère, plusieurs frères, mais pas de père, ce qui ne manque pas de surprendre. Matthieu (13, 5556) corrige : “ N'est-ce pas le fils du charpentier? Marie n'est-elle pas sa mère ? Jacques, Joseph, Simon et Jude, ne sont-ils pas ses frères? ». Jean, lui, appelle par deux fois Jésus, « le fils de Joseph » $(1,45 ; 6,42)$, et insiste sur le fait que l'on connait aussi bien l'identité de sa mère que celle de son père. Rappelons que la généalogie de Jésus proposée en Matthieu 1, et qui figure en tête du canon néotestamentaire tel qu'il en vient à être fixé au II ${ }^{\mathrm{e}}$ siècle, commence avec Abraham et se poursuit, via David, non pas jusqu'à Marie mais bien jusqu'à Joseph, “l'époux de Marie, de laquelle est né Jésus, qui est appelé Christ» (Matthieu 1, 16). Luc 3, 23-38, procède en sens inverse, de Joseph à Adam, mais n'en présuppose pas moins que Joseph est le père de Jésus. Notons encore la leçon suivante, que l'on trouve dans plusieurs témoins anciens, du même verset de Matthieu : « Jacob engendra Joseph, Joseph, auquel Marie, la vierge, était fiancée, lequel engendra Jésus, qui est appelé Christ „50. À la question des Pharisiens de Jean, la tradition néotestamentaire n'a ainsi pas de réponse univoque ; ou si réponse il y a, celle-ci vise plutôt à débouter les contradicteurs de Jésus et souligner la paternité de Joseph.

Il faut aussi noter une autre particularité de la généalogie matthéenne, qui confirme que la question fait l'objet d'un débat déjà, dans le contexte de la rédaction des Évangiles. La généalogie de Jésus mentionne, outre Marie, quatre femmes : Tamar, Rahab, Ruth et la femme d'Urie, c'est-à-dire Bethsabée. Le point commun entre ces quatre femmes, c'est évidemment que chacune d'entre elles évoque une union sexuelle irrégulière, voire scandaleuse. Tamar se fait passer pour une prostituée et couche avec son beau-père, Juda ; Rahab est une prostituée qui permet aux Israélites de prendre la ville de Jéricho dans le livre de Josué ; Ruth

Notes on Jesus and his Parents from the New Testament Gospels to the Toledot Yeshu », in R.S. Boustan et al. (dir.), Envisioning Judaism. Studies in Honor of Peter Schäfer on the Occasion of his Seventieth Birthday, Tübingen, 2013, p. 997-1017.

Voir W. Schneemelcher, New Testament Apocrypha, Louisville, 1991, vol. 1, p. 502, qui renvoi au texte syriaque du palimpseste sinaïtique. Traduction anglaise dans A. Sмiтн Lewis, A Translation of the Four Gospels, from the Syriac of the Sinaitic Palimpsest, Londres et New York, 1894. Plusieurs manuscrits grecs du Nouveau Testament ainsi que la Vetus Latina témoignent de la même leçon. C'est celle-ci que semble connaître l'interlocuteur juif du Dialogue de Timothée et Aquila, polémique anti-juive du $\mathrm{IV}^{\mathrm{e}} \mathrm{s}$. Le chrétien Timothée le reprend en citant le texte devenu entretemps canonique. Voir F.C. Conybeare, The Dialogues of Athanasius and Zacchaeus and of Timothy and Aquila, Oxford, 1898, p. xix-xxi ; S. Krauss, Das Leben Jesu nach jüdischen Quellen (supra n. 5), p. 277. 
est une veuve et une femme étrangère qui séduit Boaz, l'arrière-grand-père du roi David ; et enfin, la belle Bethsabée, dont David tomba éperdument amoureux et fit tuer le mari. Chacune de ces femmes “ pécheresses » est cependant exonérée par le récit biblique, comme par la tradition exégétique ; chacune est en fait innocente, et leurs unions irrégulières sont justifiées par leurs heureuses conséquences. De toute évidence, Marie s'inscrit, chez Matthieu, dans le prolongement de ce schéma; et l'Évangile s'attache, par cette généalogie féminine, à contrecarrer d'emblée les attaques que pourraient susciter (ou que suscitent déjà) les origines de Jésus.

On se souviendra que, chez Matthieu toujours, lorsque Joseph apprend que Marie est enceinte (par la vertu du Saint Esprit, mais il ne le sait pas encore), il hésite à la quitter (Mt. 1, 19). Intervient un ange qui l'enjoint (en rêve) d'accepter le fils auquel Marie donnera naissance, et qui lui rappelle la prophétie d'Isaïe : “Voici, la vierge sera enceinte, elle enfantera un fils, et on lui donnera le nom d'Emmanuel, ce qui signifie Dieu avec nous » (Mt. 1, 23, citant Is. 7, 14). Joseph lui-même doute. Chez Jean $(8,41)$, les Juifs rappellent à Jésus qu'eux ne sont pas nés “ de la fornication » (ek porneias), ce que ne manque pas de remarquer Origène qui voit là un mauvais jeu de mot avec l'expression “ né de la vierge » (ek parthenou $)^{51}$. Les sources chrétiennes plus tardives en effet, sont encore plus explicites, attribuant aux Juifs, parmi d'autres formes d'hostilité caractérisée (on l'a vu), un implacable scepticisme à l'égard de la virginité de Marie ${ }^{52}$. Pour l'essentiel, toutefois, ces affirmations ne font que reprendre et amplifier la donnée néotestamentaire. C'est d'ailleurs la conclusion à laquelle arrivait déjà Origène, lequel répond au Juif de Celse : “ [C]'est en déformant les textes de nos Évangiles [qu'il] déclare tant de sornettes dans ses propos contre Jésus et contre nous. „53

51 Origène, Commentaire sur l'Évangile de Jean 20, 16 (14), cité dans Krauss, “ The Jews in the Works of the Church Fathers », p. 143.

52 Voir les références supra. Voir encore Vie de Sylvestre 9 et Jérôme, Commentaire sur l'Epître à Tite III, 2, signalés par Krauss, Leben Jesu, p. 3-4; Krauss, Horbury, Jewish-Christian Controversy, p. 44. Dans les Actes de Pilate (2, 3), compilés au $\mathrm{IV}^{\mathrm{e}} \mathrm{s}$. mais sans doute à partir de traditions plus anciennes (voir Justin, 1 Apologie 35 ; 48 ; Tertullien, Apologétique 5 ; 21), les Juifs accusent ainsi Jésus d'être un sorcier (goês), avant d'ajouter : “tu es né de la fornication » (ek porneias gegenêsai). Cette accusation est d'emblée réfutée par un petit groupe de “pieux » parmi les Juifs (eulabêis ek tôn Ioudaiôn), qui affirment avoir assisté aux fiançailles de Joseph et de Marie et insistent : “il n'est pas né de la fornication» (ou gegenêtai ek porneias). De toute évidence la question demeure une source de préoccupation. 
Une accusation plus nette apparait cependant chez Tertullien, dans son traité Sur les spectacles, composé vers 200. Celui-ci s'en prend en effet à ces Juifs obstinés, qui lors du retour du Christ ne pourront que se lamenter :

Le voici, leur dirais-je, ce fils d'un charpentier ou d'une prostituée, ce destructeur du sabbat, ce Samaritain qui a un démon! Le voilà celui que vous avez acheté du perfide Judas ; celui que vous avez déchiré sous vos coups, insulté par vos soufflets, déshonoré par vos crachats, abreuvé de fiel et de vinaigre! Le voilà celui que ses disciples ont dérobé secrètement pour propager le mensonge de sa résurrection, ou qu'un jardinier a déterré furtivement, afin d'empêcher sans doute que les laitues de son jardin ne fussent foulées aux pieds par la multitude des passants. ${ }^{54}$

Selon William Horbury, Tertullien, sur deux points au moins, « se distancie du langage du Nouveau Testament pour citer des allégations juives contemporaines ", et reflète donc possiblement des polémiques réelles entre Juifs et chrétiens, à Carthage, au tournant du $\mathrm{III}^{\mathrm{e}}$ siècle $^{55}$. Je passe sur la mention du jardinier (hortulanus) qui aurait déterré le corps de Jésus, motif que l'on retrouve en effet dans les Toledot Yeshu, mais qui peut aussi simplement faire écho à Jean 20, 15, où Marie Madeleine prend Jésus ressuscité pour un jardinier qui aurait déplacé le corps du Christ, ou à d'autres traditions apocryphes ${ }^{56}$. L'élément proprement original, c'est cette allusion au fait que les Juifs considèrent Jésus comme le fils d'une prostituée, si c'est bien de cette manière qu'il faut lire quaestuariae filius. Une quaestuaria, c'est évidemment une femme qui se vend, ou qui vend son corps pour gagner sa vie - autrement dit, une " prostituée » (mulier quae corpore quaestum fecerit, selon la formule des juristes romains). Mais le terme peut aussi plus prosaïquement désigner une ouvrière, une femme salariée à la journée. Le parallèle le plus proche, il me semble, c'est encore une fois le texte de Celse, ou plutôt, du Juif de Celse, selon lequel Jésus serait né d'une "pauvre fileuse ». Le terme khernêtis, que Michel Borret, dans la collection des « Sources chrétiennes », traduit par «fileuse », peut aussi désigner, plus prosaïquement, une femme qui « vend ses services »... on n'est pas très loin de la quaestuaria de Tertullien, avec sa relative ambiguïté.

54 Tertullien, Sur les spectacles XXX, 6, avant de rappeler lui aussi que, selon les Juifs toujours, ce sont les disciples de Jésus qui ont dérobé son corps “pour propager le mensonge de sa résurrection ». Jérôme, Lettres XIV, 11 reprend ce passage et ajoute l'accusation de magie.

55 Horbury, “ Tertullian on the Jews », p. 179.

56 Meerson, Schäfer, Toledot Yeshu, vol. 1, p. 8, qui renvoient à Actes de Pilate 9, 5; 13 ; Livre de la Résurrection de Jésus-Christ par l'apôtre Barthélémy 8, 3, deux textes cependant postérieurs à Tertullien. 
Le Juif de Celse n'en dit pas plus sur ce point ; Origène se contente de rapporter encore que celui-ci badine et se moque de la mère de Jésus : serait-ce parce qu'elle était belle que Dieu s'unit à elle (Contre Celse I, 39) ? Si en effet elle était d'une race illustre, comme le prétendent les chrétiens, l'eût-elle ignoré (Contre Celse II, 32)?

\section{Le fils de Panthère}

Il est un autre point, fondamental, cependant que le Juif de Celse est le premier à rapporter ; un point qui, tel quel, ne figure chez aucun auteur chrétien ancien. Il donne en effet le nom de celui qui serait le véritable père de Jésus ${ }^{57}$. Citons encore une fois Origène, qui reprend son dialogue avec Celse, mais en introduisant cette précision supplémentaire :

Revenons aux paroles attribuées au Juif, où il est écrit que la mère de Jésus a été chassée par le charpentier qui l'avait demandée en mariage, pour avoir été convaincue d'adultère et d'être devenue enceinte des œuvres d'un soldat nommé Panthère (I, 32 ; trad. BorRet $)^{58}$.

Evidemment, que l'on admette (ou non) que Celse ait pu disposer d'une source juive “ authentique », comme je l'ai suggéré plus haut, celle-ci, pas plus que les traditions rabbiniques ultérieures, n'est en mesure de nous amener au-delà des évangiles : c'est sur la base des textes chrétiens que Celse (ou sa source) construit sa propre version de la vie de Jésus. Ce que nous avons chez Celse, c'est une lecture certes critique, voire parodique des évangiles, mais qui repose néanmoins sur ceux-ci, et en particulier (je ne suis pas le premier à l'affirmer bien évidemment) sur Matthieu. Même l'allégation d'adultère portée contre Marie peut très bien être inspirée par le fait que les évangiles eux-mêmes (on l'a vu) reflètent déjà sur ce point une certaine d'ambiguïté.

C'est cependant chez Celse qu'est pour la première fois attestée la tradition qui fait de Panthère le père de Jésus - une tradition qu'il est évidemment plus difficile d'enraciner dans le Nouveau Testament. De fait, dans les sources rabbiniques, Jésus est appelé “fils de Pandéra »(ben/bar Pandera) ${ }^{59}$. Dans une sugya bien connue du Talmud de Babylone, les rabbins se demandent s'il faut identifier ben Pandera au “ fils de Stada » (ben Stada), accusé précisément d'avoir importé des pratiques magiques d'Égypte. L’un des protagonistes de ce débat, Rav Hisda,

57 Sur Eusèbe de Césarée, Extraits prophétiques III, 10, infra.

58 Encore Origène, Contre Celse I, 33.69.

59 Tosefta, Hul. II, 22-24; Talmud de Jérusalem, Shab. 14, 4 (14d); AZ II,2 (40d-41a); Talmud de Babylone, Sanh. 67a; Shab. 104b; Ecclésiaste R. 1, 24. R. Kalmin, “ Jesus in Sasanian Babylonia ", suggère que cette tradition puisse en fait reposer en fait sur Celse. Le fait que le nom ben/bar Panthera/Pandera apparaisse toutefois dès le $\mathrm{III}^{\mathrm{e}}$ siècle (dans la Tosefta) semble cependant contredire cette idée. 
explique ce double nom (ben Pandera/ben Stada) de la manière suivante : « Le mari était Stada et l'amant Pandéra ». Non, lui répond-on, le mari était un autre ; c'est la mère, Myriam (Marie), qui était appelée Stada, une épithète qui souligne, comme le note Peter Schäfer, son statut de femme infidèle, sotah : "Sa mère était Myriam, qui laissait tomber ses cheveux (c'est-à-dire, qui était une aguicheuse). Selon ce qui est dit à Pumbeditha (l'une des deux principales académies talmudiques de Babylonie) : celle-ci s'est détournée (satat) de son mari „\$00.

Les sages débattent pour savoir si Stada était le nom du mari ou de la femme ; mais sur le fait que Pandéra ait été l'amant, tout le monde semble d'accord. À l'époque de la composition du Talmud de Babylone, au v ves., il s'agit donc là d'une tradition bien établie. On notera d'ailleurs qu'un historien arménien plus ou moins contemporain semble s'en faire l'écho, accusant précisément les Juifs d'appeler Jésus « le fils de Phatour » et d'en faire le fruit d'un “ commerce illicite » ${ }^{61}$. Pandéra, c'est évidemment aussi le nom du père de Jésus dans les Toledot Yeshu. Pour le moins, Celse témoigne de ce qu'au II $^{\mathrm{e}} \mathrm{s}$. déjà cette tradition devait exister.

Ce nom, Panthéra/Pandéra, que les Juifs, donc, associent à Jésus, a pu être diversement interprété ${ }^{62}$. Au siècle dernier, Samuel Krauss y voyait une

60 Talmud de Babylone, Sanh. 67a; Shab. 104b. Sur ce passage, voir Schärer, Jesus in the Talmud, p. 15-24. Il faut signaler que la discussion originale sur Ben Stada reprise en Shab. 104b ne se rapporte pas nécessairement à Jésus, contrairement à ce qui est souvent affirmé. Cf. T. Murcia, “Qui est Ben Stada? », Rev. Études Juives 3-4.167 (2008), p. 367-387, et désormais ID., Jésus dans le Talmud, p. 321-375.

61 V. Langlois, Collection des historiens anciens et modernes de l'Arménie, Paris, 1869, p. 191, 195, signalé par Horbury, “ Tertullian on the Jews », 178, 18n. Il faut ensuite attendre Amolon (P.L. 116, col. 169), au $\mathrm{IX}^{\mathrm{e}}$ siècle, pour retrouver cette accusation formulée de manière explicite: ...confidentes eum esse impium et filiumimii, id est, nescio cujus ethnici, quem nominant Pandera : a quo dicunt materm Domini adulteratam, et inde eum in quem nos credimus, natum. Dans les Toledot Yeshu, Pandera le plus souvent présenté comme un Juif. La tradition qui en fait, comme chez Amolon, un " païen », est cependant attestée dans quelques manuscrits, et était encore connue (entre autres) de Maïmonide au Moyen Âge ; voir Horbury, A Critical Examination, 233 et la discussion p. 405-408. L'idée que Panthéra fut un non-Juif permettra au théoricien de la race H.S. Chamberlain d'affirmer l'“ aryanité » de Jésus ; voir R. Di SEGNi, Il vangelo del ghetto (supra, n. 7), p. 120 et, de manière générale sur le « Jésus aryen », M. Olender, Les langues du Paradis : Aryens et Sémites, un couple providentiel, Paris, 1994.

62 Voir l'utile survol historiographique proposé par Murcia, Jésus dans le Talmud, p. 5798. Murcia lui-même défend l'idée que ce nom n'ait en fait aucune portée polémique et qu'il puisse s'agir du véritable patronyme de Jésus. Cf. également R.T. Herford, Christianity in Talmud and Midrash, Londres, 1903, p. 39 ; R. Di SEGNI, Il vangelo del ghetto, p. 113-116 ; D. Boyarin, Mourir pour Dieu : l'invention du martyre aux origines du judaïsme et du christianisme, Paris, 2004. 
déformation phonétique, à partir du grec pornē, pornos, dont l'emprunt est attesté par certains textes rabbiniques où l'on trouve le mot porni pour désigner la prostituée $^{63}$ : l'expression ben Pandéra serait donc un équivalent de quaestuariae filius. Ce qui, précise Krauss, n'exclut pas que cette expression puisse également jouer sur les proches sonorités de Pandéra et parthenos, la “vierge »- Krauss signalant à cet égard le commentaire d'Origène, selon lequel les Juifs affirment : “Toi qui prétends être né d'une vierge, tu es né d'une prostituée (ek porneias)» (mais évidemment, Origène ne fait ici que reprendre une accusation que l'on trouve déjà chez Jean [8, 41], j’y ai fait allusion).

L'idée que le nom Panthéra/Pandéra puisse dériver du grec parthenos est aussi suggérée depuis longtemps ${ }^{64}$. On a voulu voir aussi un jeu de mot qui ferait de Marie ou de son amant, une panthère (panthêr, panthêros), animal dionysiaque qui, dans les sources antiques incarne, on le sait, une forme de séduction érotique ${ }^{65}$. Jésus serait donc le fils d'une panthère, ce qui, soit dit en passant, sous-entendrait aussi sa bâtardise, la panthère étant réputée, dans l'antiquité, s'accoupler avec d'autres espèces et donner naissance à des animaux-bâtards, comme le léopard, dont la

63 Krauss, Leben Jesu, p. 276 ; ID., “ The Jews in the Works of the Church Fathers », p. 143. Cf. M. Jastrow, A Dictionary of the Targumim, the Talmud Babli and Yerushalmi, and the Midrashic literature, London, 1903, p. 1147.

64 Ainsi déjà F. Nıтzsch, “Über eine Reihe talmudischer und patristischer Täuschungen, welche sich an den mißverstandenen Spottnamen Ben-Pandira geknüpft „,Theologische Studien und Kritiken : Beiträge zur Theologie und Religionswissenschaft 13 (1840), p. 115-120, sp. 116 (qui renvoie sur ce point à BLEEK) et P. Cassel, Apologetische Briefe I: Panthera-Stada-onokotes: Caricaturnamen Christi unter Juden und Heiden, Berlin, 1875, repris dans ID., Aus Literatur und Geschichte, Berlin et Leipzig, 1885, sp. 334. Cf. J. Klausner, Jésus de Nazareth : son temps, sa vie, sa doctrine, Paris, 1933, p. 23.

65 Àce sujet, voir M. Detienne,Dionysos mis àmort, Paris, 1977, p. 93-98. Il faut cependant noter que le terme d'usage courant est pardalis et non panther. Voir H. Laible, Jesus Christus im Thalmud, Berlin, 1891, p. 24-25. Sснӓғеr, Jesus in the Talmud, p. 8, fait remonter cette interprétation à F. Nitzsch. On la trouve cependant déjà chez J.J. Huldreich, Historia Jeschuae Nazareni a Judaeis corrupta, Liège, 1705, p. 8, dans une note reprise par BASNAGE, Histoire des Juifs, tome V, p. 268 : “ On a même quelque raison de croire (que ce nom) n'a été imaginé que pour rendre la Naissance du Messie plus odieuse. Le Panther, ou le Mâle de la Panthère, est un Animal farouche \& cruel, \& qui s'accouple avec la Lionne, \& de là naît le Leopard ... On cite même l'Ouvrage manuscrit d'un Rabbin, lequel dit, que comme le Leopard se forme par le mélange d'espèces différentes ; Diversam confusa Genus Panthera Camelo ; Jésus-Christ est sorti d'un Soldat (Grec) \& d'une Femme juive. Ceux qui comptent Panther au Rang des Aieuls de Jésus-Christ, donnent donc dans le Piége que les plus grands Ennemis de la Religion Chrétienne leur ont tendu. » 
robe est pour cette raison bigarrée ${ }^{66}$. (Il faut bien sûr rappeler ici que ce que les Anciens appellent “ panthère » ne correspond pas nécessairement à l'animal que nous désignons par ce nom aujourd'hui). Le jeu de mot aurait plus tard été oublié et le nom serait entré dans l'usage commun : celui-ci n'est plus que la relique d'un vieux trait d'esprit dont le sens s'est perdu ${ }^{67}$.

Des explications plus prosaïques ont également été avancées, en particulier par Adolf Deissmann, lequel signalait que les noms Panther, Panthera, Pantheras sont relativement courants parmi la soldatesque romaine des premiers et deuxième siècles ${ }^{68}$. Un certain Tiberius Julius Abdes Pantera, originaire de Sidon, en Phénicie, nous est notamment connu par une inscription funéraire découverte en 1859, avec les pierres tombales de neuf autres soldats romains, à Bingen am Rhein, en Rhénanie et aujourd'hui conservées à la Römerhalle de Bad Kreuznach (CIL XIII, 7514) - ce qui n’a pas manqué de nourrir certaines spéculations pseudosavantes suggérant qu'on avait trouvé là la tombe du vrai père de Jésus ${ }^{69}$. Quoi qu'il en soit, le nom n’aurait pas, selon Deissmann, été inventé par les Juifs dans le but de se moquer de la conception de Jésus. Cette opinion a toutefois été récemment rejetée par Daniel Boyarin et Peter Schäfer, qui préfèrent tous deux revenir à l'idée d'un jeu de mot : il suffit, nous dit Schäfer, d'inverser deux lettres pour transformer parthenos en panthêros (ce qui soulève cependant un problème orthographique $\left[\right.$ epsilon/êta]qui, déjà à cette époque, se laisse aussi entendre à l'oral ${ }^{70}$. Selon Boyarin, " ce serait là un bel exemple de cette forme de plaisanterie juive sur les chrétiens et les païens que Lieberman appelait "cacophémisme" ", qui consiste à se moquer des termes sacrés païens ou chrétiens en leur donnant une consonance négative $^{71}$. Schäfer va plus loin, en suggérant qu'en inversant les lettres du mot parthenos, les rabbins (sic) appliquent une forme de lecture inversée à caractère imprécatoire, une pratique « magique » attestée par ailleurs, “ transformant » la conception virginale de Jésus en une naissance des plus ordinaires, et « faisant »

66 Voir Pline, Histoire naturelle VIII, 77 ; Isidore de Séville, Étymologies XII, 2, 8-9.

67 En ce sens Herford, Christianity in Talmud andMidrash, p. 39-40. Selon Herford le « a » de Panthera reflèterait d'ailleurs l'article araméen.

68 A. Deissman, “ Der Name Panthera », in Orientalistische Studien. Theodor Nöldeke zum siebziegsten Geburtstag, Gieszen, 1906, vol. 2, p. 871-875. On notera que pour la Souda,

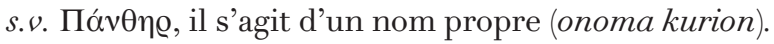

69 Voir par exemple J.D. TAвоR, The Jesus Dynasty: Stunning New Evidence About the Hidden History of Jesus, Londres, 2006, p. 64 et suivantes. Notons avec Murcia, Jésus dans le Talmud, p. 62, que cette hypothèse était déjà formulée par Sмiтн, Jesus the Magician, p. 47.

70 Boyarin, Mourir pour Dieu, suivi par Schäfer, Jesus in the Talmud, p. 98.

71 Boyarin,MourirpourDieu, qui n'explique cependant pas ce que serait cette « consonance négative ». Je n'ai pas été en mesure de retrouver la citation de Lieberman. 
de Jésus le fils illégitime d'une femme juive et d'un vulgaire soldat romain appelé Panthera... ${ }^{72}$ Reste que panthêr-, panthêros n'est pas panthêra.

Quelle que soit la validité de l'argument linguistique, il faut noter que l'analogie n’est pas passée inaperçue des auteurs chrétiens anciens, qui semblent avoir été sensibles aux potentialités polémiques du jeu de mot associant Jésus, ou son père, à la panthère. Origène se contentait de rejeter cette “ fable » (mythos) inventée par les Juifs “ pour nier la conception miraculeuse par le Saint-Esprit », ajoutant : “ Il était tout naturel que ceux qui n’admettent pas la naissance miraculeuse de Jésus forgent quelque mensonge » ${ }^{73}$. On n’en est que plus surpris de voir que le nom finira par entrer dans la généalogie officielle du Christ, plusieurs auteurs chrétiens inscrivant Panthéra au rang des ancêtres de Marie ${ }^{74}$. C'était peut-être là le meilleur moyen de répondre à l'opinion de ceux qui en faisaient son amant.

\section{Le Christ est une panthère}

C'est peut-être aussi pour répondre à ceux qui mésinterprétaient ou trouvaient dans le nom, Panthéra, matière à se moquer de Jésus, que plusieurs auteurs chrétiens en proposent une étymologie remarquablement sophistiquée, associant exégèse biblique et traditions classiques relatives, précisément, à la panthère. Ainsi le Physiologos, célèbre bestiaire chrétien composé entre le $\mathrm{III}^{\mathrm{e}}$ et le $\mathrm{Iv}^{\mathrm{e}}$ siècle, qui, à propos d'un verset d'Osée - « Je suis désormais comme une panthère pour Ephraïm »(Os. 13, 7) - propose :

(La panthère) aime énormément toutes les bêtes, et elle ne déteste que le dragon. Elle est bigarrée comme la tunique de Joseph, très belle et très paisible. Quand elle a mangé et qu'elle est rassasiée, elle va dormir dans sa tanière ; et le troisième jour elle sort de son sommeil et d'une voix forte pousse un cri et un rugissement. Et de loin comme de près les (bêtes) entendent sa voix. De sa voix s'exhale partout un parfum d'aromates. Elles s'approchent de la panthère en suivant le parfum de sa voix. C'est ainsi que le Seigneur Jésus Christ s'est relevé d'entre les morts le troisième jour et il a été pour nous un parfum répandu partout... L'Écriture ne comporte donc rien d'inconsidéré sur les oiseaux et les bêtes (Physiologos 16 ; trad. Zucker).

72 SchäFER, Jesus in the Talmud, p. 98.

73 Origène, Contre Celse I, 32.

74 Épiphane, Panarion 78, 7, 5 ; Didascalie de Jacob I, 42 ; André de Crète, Oraison sur la circoncision du Seigneur (P.G. 97, col. 916); Jean de Damas, La Foi orthodoxe IV, 14 ; Épiphane le moine, Vie de Marie (P.G. 120, col. 190). Voir Strack, Jesus, die Häretiker und die Christen, p. 10-13. 
Une recension latine ajoute: “ La vraie panthère est notre Seigneur JésusChrist „ ${ }^{75}$. La panthère, dont le doux parfum ${ }^{76}$ attire à soi toutes les créatures, devient ainsi une figure du Christ - une figure évidemment susceptible d'avoir été mal comprise par ceux qui sont de toute façon incapables de lire correctement l'Écriture.

C'est très clairement ce que dit Eusèbe de Césarée, dans l'un de ses premiers écrits, les Extraits prophétiques au sujet du Christ, où il se réfère au même verset d'Osée. Après avoir cité les Physica de Didyme (un grammairien alexandrin du $\mathrm{I}^{\mathrm{er}}$ siècle. avant notre ère) au sujet de la panthère, Eusèbe explique : “(Cet animal) métaphorise la puissance du Logos divin et le parfum exhalé par celui-ci, il serait trop long maintenant de l'exposer en détail ». Il ajoute :

Le passage devrait être opposé à ceux de la circoncision qui disent selon quelque calomnie et injure que c'est notre Sauveur et Seigneur Jésus Christ qui est né d'une panthère ; ayant interprété cela selon une tradition doctrinale plus secrète, peut-être ne l'appliquent-t-ils pas au sens parce qu'ils ne fixent pas leur attention à la donnée proposée par la prophétie, dans laquelle le Seigneur se donne à lui-même le nom de panthère (Extraits prophétiques III, 10 ; trad. Jaubert Philippe, modifiée).

Eusèbe, évidemment, connaissait Origène, chez lequel il a pu trouver « la fable de l'adultère de la Vierge avec Panthère »" ${ }^{77}$. De toute évidence, non seulement le caractère polémique (ou potentiellement polémique) du nom Panthéra ne lui a pas échappé, mais il se sera aussi senti obligé (comme le Physiologos avant lui) d'expliquer le sens véritable de cette appellation du Christ, que les Juifs n'ont pas comprise.

On aurait donc là un double renversement : un nom fabriqué pour se moquer de la naissance virginale, mais que les chrétiens finissent par prendre pour argent comptant, et dont ils fabriquent à leur tour une interprétation susceptible d'être renvoyée aux Juifs... On notera cependant que le lien entre Panthéra/Pandera et la panthère n'apparaît nulle part dans la littérature rabbinique - si ce n'est, peut-être, une allusion obscure au léopard (que la tradition antique, rappelonsle, présente comme le fruit d'une union entre la panthère et le lion) dans une discussion sur... le statut des bâtards ${ }^{78}$.

75 A. Zucker (éd.), Physiologos. Le bestiaire des bestiaires, Grenoble, 2004, p. 130.

76 Sur l'odeur de la panthère, voir Aristote, Histoire des animaux IX, 6 ; Problèmes XIII, 4 ; Théophraste, Sur les plantes VI, 5, 2 ; Élien, De la nature des animaux V, 40 ; Pline, Histoire naturelle VIII, 23. Sur la panthère dans l'iconographie chrétienne ancienne, voir F. Massa, Tra la vigna e la croce : Dioniso nei discorsi letterari e figurativi cristiani (II-IV secolo), Stuttgart, 2014, p. 142-143.

77 Eusèbe de Césarée, Histoire Ecclésiastique V, 26, 2.

78 Talmud de Babylone, Kid., 70a. 


\section{Jésus entre chrétiens et Juifs}

Dans les Toledot Yeshu, Panthéra/Pandera prend vie et devient un personnage à part entière, serait-ce de manière éphémère. Les textes le décrivent comme un vaurien, un homme de mauvaise vie, un coureur ou un proxénète. Dans la version éditée par J.C. Wagenseil en 1681, on le voit pleurer dans les jupons de sa mère, ne sachant comment séduire la belle voisine, Myriam, dont il est désespérément amoureux. La scène même de la conception de Jésus, la gestation du christianisme, s'apparente à un viol : après avoir fait boire son mari et s'être assuré qu'il était endormi, Pandéra s'introduit chez Myriam et couche avec elle ${ }^{79}$. Dans la version éditée, en 1705, par le théologien bâlois J.J. Huldreich, l'histoire prend encore une autre tournure : Myriam est une très belle femme, jalousement gardée par son mari qui craint qu'elle ne lui soit volée. Ce qui n'empêche pas Pandéra d'escalader la tour où Myriam est enfermée et de s'enfuir avec elle. Lorsque, devenu grand, Jésus apprend qu'il est né de cette union adultère, il torture sa mère, assassine son père et s'enfuit en Galilée où il a la carrière que l'on sait ${ }^{80}$.

Nous avons naturellement tendance à considérer un récit comme les Toledot $Y e s h u$, dans lequel un groupe caricature sans complexe les récits fondateurs de l'autre et par là même, souligne sa propre supériorité morale et religieuse, comme relevant du genre polémique. Les Toledot Yeshu sont, à n'en pas douter, une tradition polémique; mais cette affirmation nécessite d'être creusée. Les polémiques inter-religieuses reflètent la nécessité, pour un groupe, d'établir et de maintenir les frontières avec l'“ autre ». Mais elles témoignent aussi de la porosité de ces frontières, et surtout, des angoisses liées à cette porosité. Il n'y a somme toute rien de surprenant à ce que les Juifs, confrontés à l'émergence, puis au triomphe du christianisme, aient développé un discours qui renverse le discours chrétien et restitue la prééminence du judaïsme ${ }^{81}$. Il faut cependant insister sur le

79 À ce sujet, je me permets de renvoyer à D. BARBu, « The Case About Jesus : (Counter-) History and Casuistry in Toledot Yeshu ", à paraître dans C. Ginzburg (dir.), A Historical Approach to Casuistry. Norms and Exceptions in Comparative Perspective, Londres. Voir également N.E. Latteri, “ Playing the Whore : Illicit Union and the Biblical Typology of Promiscuity in the Toledot Yeshu Tradition ", Shofar 33.2 (2015), p. 87-102 ; S.Kattan Gribetz, "The Mothers in the Manuscripts: Gender, Motherhood, and Power in Toledot Yeshu », in Barbu, Deutsch (dir.), Toledot Yeshu in Context, Tübingen, à paraître.

80 Sur cette version du récit, A. Yoffie, "Observations on the Huldreich Manuscripts of the Toledot Yeshu ", in Schäfer et al.(dir.), Toledot Yeshu ... Revisited, p. 61-77. Ce texte se distingue en fait par son caractère extrême, la plupart des autres versions témoignant d'une relative sympathie à l'égard de Marie, le plus souvent décrite comme une victime ; voir les références données dans la note qui précède.

81 Voir D. Biale, "Counter-History and Jewish Polemics Against Christianity : The Sefer Toldot Yeshu and the Sefer Zerubavel », Jew. Soc. Stud. 6.1 (1999), p. 130-145. 
fait que ces textes s'adressent d'abord à un public juif et non à un public chrétien. En ce sens, les Toledot visent moins à attaquer l'“ autre » qu’à fournir aux Juifs les clés d'une histoire dont les suites se font chaque jour ressentir ; une histoire faut-il le rappeler? - qui n'est pas à parts égales ${ }^{82}$.

Les Toledot Yeshu n'en révèlent pas moins que les Juifs aussi se sont pensés au miroir de l'“ autre » chrétien. Serait-ce indirectement, ce sont bien à des « sources chrétiennes », comme l'affirmait Krauss, que puisent ces textes qui détournent l'histoire de Jésus pour en faire un puissant contre-discours sur les origines du christianisme, et plus généralement, sur les dangers de l'hérésie, de la magie et des pseudo-messies. Évidemment, ce détournement répond aussi au détournement chrétien des Écritures juives, à ce discours qui fait du christianisme le « véritable Israël » et qui décrit les Juifs, au mieux, comme des témoins de la vérité chrétienne, au pire, comme des vestiges du passé, “ un peuple à la nuque raide » légitimement soumis au joug des chrétiens parce qu'il a refusé de reconnaître la messianité de Jésus $^{83}$. Sans doute les Toledot n'ont-ils que tardivement pris la forme qu'on leur connaît, celle d'un “ roman » élaboré à partir d'un savant mélange d'anecdotes rabbiniques et de traditions apocryphe ; un “ roman » qui transforme la vie de Jésus en une farce burlesque dont les épisodes successifs retracent les péripéties d'un enfant conçu dans l'adultère qui décide de se proclamer fils de Dieu et s'attache les foules crédules en usant de magie, avant d'être mis à mort par les sages conformément aux injonctions bibliques contre ceux qui incitent le peuple à l'idolâtrie (Dt. 13, 6-11). De fait, je l'ai dit, un tel « roman » n'est pas attesté avant le $\mathrm{Ix}^{\mathrm{e}}$ siècle, époque à laquelle il est cependant déjà largement diffusé. C'est avec Agobard et Amolon que commence l'histoire des Toledot à proprement parler. Il convient de rester prudent quant à ce qui précède, quand bien même il est vraisemblable que nombre d'éléments constitutifs du récit ont dû circuler aux époques antérieures. Cependant, les témoignages survolés ici, j’insiste, reflètent moins des interactions avec des Juifs “ réels » qu'avec des Juifs “ textuels », des Juifs qui sont d'abord le produit d'une herméneutique chrétienne de l'، Ancien Testament » ${ }^{84}$. Pour l'essentiel, le « discours juif » que ces témoignages rapportent ne fait que reprendre et amplifier les objections soulevées par les adversaires de

82 Voir récemment $\mathrm{Ph}$. Bongeaud, “Antijudaïsme et théorie des figures : plagiat par anticipation, vol de langage et histoire des religions ", Asdiwal. Rev. Genevoise Anthropol. Hist. Relig. 11 (2016), p. 33-46.

83 Voir Justin, Dialogue 11, 5 ; Augustin, Cité de Dieu XVIII, 46. En général, voir M. Simon, Verus Israel: étude sur les relations entre chrétiens et juifs dans l'Empire romain (135425), Paris, 1948 et plus récemment, J. CoHen, Living Letters of the Law : Ideas of the Jew in Medieval Christianity, Berkeley, 1999. Voir également Nirenberg, Anti-Judaism.

84 M. Kriegel, "L'esprit tue aussi. Juifs "textuels" et Juifs "réels" dans l'histoire », Ann. Hist. Sci. Soc. 69.4 (2014), p. 875-899, avec CoHen, Living Letters of the Law. 
Jésus dans les évangiles mêmes ${ }^{85}$. Seul ce nom, Panthéra, fournit la “ trace » d'un discours qui ne s'enracine pas dans le Nouveau Testament, d'un "hors-texte ", pour le dire avec Carlo Ginzburg, dont l'écho lointain nous parvient à travers le double filtre de Celse et d'Origène ${ }^{86}$. Un nom dont les Juifs semblent toutefois avoir perdu le sens et dont les chrétiens finiront par faire une image du Christ ${ }^{87}$.

\section{Daniel Barbu}

Institut d'études juives, Université de Bern

CNRS, PSL, UMR 8584, Laboratoire

d'études sur les monothéismes

7 Rue Guy Môquet

FR-94801 Paris Villejuif

daniel.barbu@cnrs.fr

85 Pour une opinion différente, Horbury, A Critical Examination, 354-437, pour lequel les témoignages fournis par les sources antiques suggèrent qu'une sorte de proto-Toledot circulait dès le III ${ }^{e} \mathrm{~s}$.

86 Voir C. Ginzburg, "La voix de l'autre », in ID., Rapports de force : histoire, rhétorique, preuve, Paris, 2003, p. 71-82.

87 Je remercie Philippe Borgeaud et Francesco Massa pour leur aide précieuse dans la rédaction de ce texte et pour leurs relectures. 